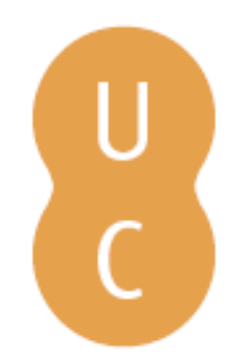

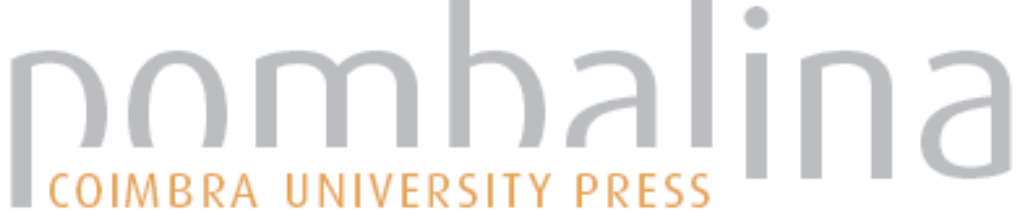

\section{Sobre a inferência em estudos de opinião}

Autor(es): Lages, Mário F.

Publicado por: Imprensa da Universidade de Coimbra; Gravida

URL

persistente: URI:http://hdl.handle.net/10316.2/32617

DOI: $\quad$ DOI:http://dx.doi.org/10.14195/978-989-26-0485-5_6

Accessed : $\quad$ 26-Apr-2023 11:50:01

A navegação consulta e descarregamento dos títulos inseridos nas Bibliotecas Digitais UC Digitalis, UC Pombalina e UC Impactum, pressupõem a aceitação plena e sem reservas dos Termos e Condições de Uso destas Bibliotecas Digitais, disponíveis em https://digitalis.uc.pt/pt-pt/termos.

Conforme exposto nos referidos Termos e Condições de Uso, o descarregamento de títulos de acesso restrito requer uma licença válida de autorização devendo o utilizador aceder ao(s) documento(s) a partir de um endereço de IP da instituição detentora da supramencionada licença.

Ao utilizador é apenas permitido o descarregamento para uso pessoal, pelo que o emprego do(s) título(s) descarregado(s) para outro fim, designadamente comercial, carece de autorização do respetivo autor ou editor da obra.

Na medida em que todas as obras da UC Digitalis se encontram protegidas pelo Código do Direito de Autor e Direitos Conexos e demais legislação aplicável, toda a cópia, parcial ou total, deste documento, nos casos em que é legalmente admitida, deverá conter ou fazer-se acompanhar por este aviso.

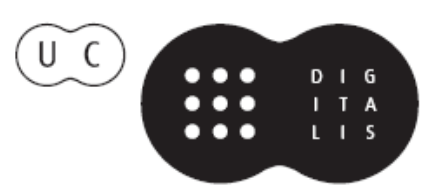


(Página deixada propositadamente em branco) 
MARIA PAULA SERRA DE OLIVEIRA

Coordenadora

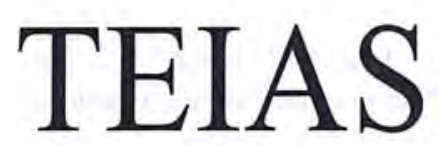

MATEMÁTICAS

Frentes na Ciência e na Sociedade 
(C) Gradiva - Publicações, L. da / Imprensa da Universidade de Coimbra, 2004 Coordenação editorial: Maria Paula Serra de Oliveira

Tradução: Artur Soares Alves

Carlota Isabel Leitão Pires Simões

Francisco José Craveiro de Carvalho

João Filipe Cortez Rodrigues Queiró

José Miguel Dordio Martinho de Almeida Urbano

Lia Sandra dos Santos

Mário da Silva Rosa

Paulo Eduardo Aragão Aleixo Neves de Oliveira

Revisão do texto: Isabel Pedrome

Capa: António Barros [Imprensa da Universidade. Coimbra], com imagem de

E. M. de Melo e Castro, "Fract 010 explod MC", Dezembro de 2003

[Fractal original gerado no Fractint com tratamento no Photoshop 7.0]

Infografia: Estúdios Estímulus [design]

Paginação: António Resende e Victor Hugo Fernandes

Impressão e acabamento: G.C. - Gráfica de Coimbra, L. da

Reservados os direitos para Portugal por:

Gradiva - Publicações, L. ${ }^{\text {da }}$ e Imprensa da Universidade de Coimbra

Gradiva - Publicações, L. ${ }^{d a}$

Rua Almeida e Sousa, 21, r/c, esq. • 1399-041 Lisboa

Telefs. $213974067 / 8 \cdot 213971357 \cdot 213953470$

Fax $213953471 \cdot$ Email: gradiva@ip.pt

URL: http://www.gradiva.pt

Imprensa da Universidade de Coimbra

Rua Antero de Quental, 195 • 3000-033 Coimbra

Telefs. 351239853110

Fax 3512398531 19 e-mail: fjrpress@ci.uc.pt

URL: http://www.imp.uc.pt

ISBN: 972-662-970-5

1." edição: Maio de 2004

Depósito legal n. ${ }^{\circ} 210431 / 04$

OBRA PUBLICADA COM O PATROCÍNIO DE:

CENTRO DE MATEMÁTICA DA UNIVERSIDADE DE COIMBRA DEPARTAMENTO DE MATEMÁTICA DA UNIVERSIDADE DE COIMBRA

FCT Fundação para a Ciência e a Tecnologia

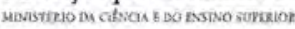


Mário F. Lages

Director do Centro de Estudos

e Sondagens de Opinião da

Faculdade de Ciências Humanas

da Universidade Católica

\section{Sobre a inferência em estudos de opinião}

\section{INTRODUÇÃO}

Os problemas relacionados com a compreensão dos comportamentos humanos, designadamente os referentes à opinião pública, não são de solução simples, sendo a matemática apresentada, por vezes, como a vara de condão capaz de transformar o pensamento impreciso em conhecimento seguro. A nível básico, certamente o será, a acreditarmos em Bertrand Russell, que afirma serem a «matemática e a lógica [...] a mesma coisa» (Russel 1972 [1903]: v). Possivelmente por isso é que todas as ciências humanas a têm vindo a utilizar para dizer com rigor o que a linguagem vulgar não faz de maneira convincente. Os casos mais claros são os da demografia e da economia, esta tratada noutro texto desta colectânea. Quanto à demografia, pode dizer-se que teve um desenvolvimento paradigmático, sendo uma das ciências humanas que mais têm utilizado a matemática. Basta recordar os trabalhos sobre a mortalidade de Breslau, por Edmund Halley, nos já longínquos idos de 1693, a lei do crescimento geométrico da população de R. Malthus (1798) e as suas várias correcções, designadamente logísticas, desde Verhulst (1838), os contributos de A. Lotka (1998) para a teoria das populações estáveis, os logitos de sobreviventes de Brass (1974), ou a modelização da fecundidade de Coale e Trussell (1978).

$\mathrm{O}$ argumento poderia ser desenvolvido quase indefinidamente, sem qualquer vantagem, porém, já que a questão nele subjacente está nos 
antípodas do que nos interessa aqui. De facto, os modelos globais dos comportamentos, entre os quais os demográficos, levam a esquecer não só a pluralidade e complexidade das interacções comportamentais, mas também a sua não linearidade. Assim, os pressupostos de uma teoria determinista da história e dos comportamentos - de que são exemplos os estádios de Vico, Comte e Frazer - ao estabelecer sequências obrigatórias e universais, reduzem essa complexidade a uma evolução pré-determinada.

Tais perspectivas, fundamentalmente macroteóricas, não podem ter em conta que os fenómenos colectivos dependem de decisões nem sempre racionalizadas ou automáticas. O jogo das interacções, diferencialmente definido pelos actores sociais e teorizado pela sociologia compreensiva, leva a dizer que a conclusão não está sempre contida nas premissas. Por isso é que, se o bater das asas da célebre borboleta de Pequim provoca uma tempestade em Nova Iorque, a potenciação do efeito de eco é notória nos fenómenos sociais, como podemos deduzir de um exemplo recente: a visita de Ariel Sharon à zona das mesquitas de Jerusalém levou a uma nova Intifada, que levou às balas israelitas, que levou à morte de uma criança diante das câmaras da televisão e perante a protecção impotente do pai, que levou ao linchamento de dois soldados israelitas em Ramalah, que levou à quase-guerra hoje em curso no Médio Oriente.

Esta sequência perversa e não previsível dos actos humanos, exacerbados no seu significado pelos sentimentos mais diversos, muitas vezes vividos à flor da pele das sensibilidades colectivas, manifesta, pela sua natureza excessiva e extrema, quanto a percepção das acções alheias condiciona, numa perspectiva weberiana, toda a interacção humana e social. Por isso se insiste cada vez mais em que a indeterminação dos actos humanos tem a sua correspondência nos próprios fenómenos naturais, sobretudo a nível micro. A incerteza não pode deixar de ser introduzida na própria definição da realidade e nas técnicas de análise a que ela pode ser submetida.

Este conjunto de considerações permite centrar a intenção deste trabalho: ilustrar os pressupostos da análise das atitudes expressas em sondagens por questionário, o instrumento que os sociólogos têm vindo a privilegiar para a captação das circunstâncias definidoras dos comportamentos. Tentarei, por isso, apresentar alguns contornos da produção científica em sociologia, pondo em destaque alguns enviesamentos que a estatística pode produzir. No âmago do tema está uma teia de concepções e de métodos, de não fácil destrinça, tal como a realidade sobre a qual o sociólogo se debruça. Na sequência destas reflexões farei a sua aplicação aos resultados de uma sondagem. 
E porque de teia conceptual, que não só matemática, se trata, coloco algumas questões sobre os processos de produção dos factos que constituem a matéria dos estudos de opinião. Sendo eles o primeiro objecto de construção teórica, convirá reflectir sobre os instrumentos que os originam e sobre o seu efeito na produção da realidade.

$\mathrm{Na}$ base de grande parte das empiria sociológica moderna está o questionário, um instrumento não inocente que resulta de várias escolhas, todas elas sujeitas a imprecisões, em parte decorrentes do tipo de variáveis que $o$ estruturam. O investigador tem muitas vezes de se contentar com variáveis nominais, ou, quanto muito, ordinais, o que naturalmente se reflecte no poder das estatísticas utilizáveis. Por outro lado, a matemática tem vindo a produzir métodos específicos de análise de dados. Contudo, as teorias que com eles podem ser construídas nem sempre resistem a uma crítica rigorosa. De resto, muitas vezes, os métodos afastam-se do que o cientista considera intuitivo, dificultando a sua utilização inteligível. Os resultados são, assim, inseguros e pouco sustentados teoricamente. Acontece mesmo que a teoria não é suficiente para evitar desvios. De facto, nem todos os olhares conseguem ver correctamente a realidade. O olhar teoricamente cego certamente o não faz.

Relacionado com estas observações está o facto de que, em sociologia, como se deduz do que foi dito acerca da perspectiva compreensiva, não é fácil observar o preceito da ruptura epistemológica que Bachelard recomendava como condição da produção científica. A interpretação do actor acerca da aç̧ão, própria e alheia, faz parte integrante da situação e da interacção nela produzida. Além disso, em qualquer inquérito de opinião, por mais clara e inequívoca que seja a pergunta, a resposta é sempre dada em função do entendimento circunstancial que dela faz o inquirido. Esta circunstância incorpora contextos vivenciais que constituem o pano de fundo em que os significados são entrevistos a partir de uma experiência pessoal sobredeterminada culturalmente. Por isso é pouco provável que todos os entrevistados entendam todas as perguntas da mesma maneira. Os comportamentos têm uma forte componente de ambiguidade. E o próprio actor social pode ter duas interpretações diferentes dos mesmos factos em dois momentos da sua vida, sejam eles separados por dias, horas ou mesmo minutos. Não é invulgar alguém mudar de opinião no decurso de uma entrevista. O questionário e a relação entrevistador-entrevistado podem contribuir para isso.

O distanciamento entre a empiria e a teoria que a ruptura epistemológica supõe não é, pois, facilmente atingido. A teoria, por mais implícita 
que seja, do actor acerca da sua própria acção faz parte integrante desta. Desde W. Thomas que se sabe, segundo a interpretação de R. Merton (1957: 421), que quando alguém toma uma definição da situação como real, ela se torna real nas suas consequências. Conquanto, na primitiva formulação de Thomas, essa definição, de natureza individual, pudesse admitir contradições (cf. Thomas e Znaniecki 1998: 12), não deixa de ser importante para o nosso argumento dizer que toda a definição da situação faz parte integrante do sistema de acções e reacções que determinam o seu desenvolvimento, com inclusão destas teorias implícitas. Por outro lado, a realidade sociológica é feita de imagens implicadas, transmitidas por quem está interessado na sua definição. Os factos sociais não são constituídos apenas por expressões de sentimentos, atitudes e comportamentos, mas também pelas configurações dos meios em que emergem. E tanto assim é que tomamos, às vezes, por realidades, as imagens que se formam e deformam no ecrã das identificações pessoais e colectivas.

Assim, as mediações expressivas são como artes de engano, não porque consciente, obrigatória e propositadamente o queiram ser, mas porque nem sempre está realizado, entre outras coisas, o processo de auto-identificação prévia do respondente, sendo certo que só ele poderia induzir a resposta "verdadeira». A rapidez do inquérito, a relação interpessoal que o produz, a invasão da privacidade que representa, são circunstâncias que dificultam a expressão sincera, mesmo por quem não está na defensiva. Por outro lado, o inquérito pode produzir no respondente uma clara consciência de realidades e atitudes desconhecidas, sendo esta tomada de consciência acompanhada de conflitos interiores que o podem levar a produzir uma imagem ideal de si - do que é, faz, sente, pensa e sabe -, tanto para salvar a face como para melhorá-la. Pode mesmo acontecer que se convença de que a realidade assim definida é exacta.

Sendo, além disso, o inquérito um momento de afirmação da conformidade com o que é correcto do ponto de vista político, ético ou comunitário, a definição das atitudes nem sempre é lógica e coerente. O espaço de formação e expressão da opinião é, de facto, multidimensional. $\mathrm{E}$ as linhas de força que percorrem este espaço não são facilmente destrinçadas por quem está sob o império da pergunta incontornável, a que é necessário responder imediatamente.

Tudo isto é relevante para o nosso propósito, designadamente no caso em que a principal preocupação do cientista é definir o que é o «homem médio», como acontece em certas metodologias tipológicas - à maneira do que já se propunha A. Quételet - por mais diversificado que este homem seja, a partir de uma multiplicidade de critérios analiticos. 
Ora as identidades modernas ou pós-modernas são cada vez mais circunstanciais e contextuais. Num momento o actor age segundo a norma, noutro está na moda, no seguinte faz parte da excepção; aqui está em uníssono com alguém, acolá com outrem. Desta sorte, há cada vez menos conformidades absolutas e permanentes. A busca da originalidade e da diferença - ou melhor, de uma identidade diferencial - constitui uma das características dominantes dos comportamentos actuais, não só das vanguardas, mas também das classes médias, ou mesmo baixas, que anseiam pelo reconhecimento e pela notoriedade, ao contrário do que acontecia com as personalidades tradicionais e endonómicas dominantes entre nós, respectivamente nas comunidades rurais e nas classes médias urbanas, até ao último quartel do século XX. Nem a simplicidade estrutural das primeiras, nem os ditames conservadores das segundas proporcionavam o debate de ideias e as mudanças rápidas que hoje acontecem em quase todos os meios sociais.

Nesses contextos, em grande parte ultrapassados, as instituições, com os seus amplos refolhos de ditames e sanções, formavam um complexo concêntrico, quase concentracionário, fortemente condicionador dos comportamentos. Por isso eles eram relativamente previsíveis. Hoje, porém, a cultura dominante exprime-se em fragmentações aptitudinais e comportamentais, em conflitualidades ideológicas e religiosas, em contradições éticas e doutrinais, em impasses vários nas relações sociais. $\mathrm{E}$, por mais que se tente congraçar as oposições e as diferenças, a acção humana é simultaneamente imbricada e contrastante, tanto ao nível das sociedades, das comunidades e dos grupos, como do próprio indivíduo. Daí a dificuldade na manutenção consistente de comportamentos e opiniões, o que apela para modelos interpretativos necessariamente complexos.

\section{IMPRECISÃO, IMPLICAÇÕES FRACAS E PARADOXOS}

Tudo isto tem implicações óbvias nos modelos de análise. Mas a questão fundamental é saber se os comportamentos podem ser matematizados, o que poderá parecer supérfluo, já que, de uma maneira ou de outra, isso tem sido feito. Não se deixará, no entanto, de notar que há quem encontre dificuldades no argumento. Coleman, por exemplo, na sua já clássica Introduction to Mathematical Sociology (1964: 3), diz que o isomorfismo entre as estruturas matemáticas e as ciências da natureza não se verifica em relação à «ciência social». De facto, «as teorias verbais 
e os resultados da investigação [...] são definidos de maneira tão vaga ou tão fraca que é difícil traduzi-los em linguagem matemática, e, quando traduzidos, frequentemente não mostram o seu isomorfismo com partes fortes da matemática». O problema estaria em que, «[e]m geral, a construção teórica em sociologia tem-se confinado à riqueza - e à ambiguidade - da linguagem ordinária» (Coleman 1964: 3).

Estando a polissemia no âmago da realidade social e sendo a regularidade, em parte, uma abstracção, é correcto dizer que os comportamentos humanos são cada vez mais refractários a lógicas deterministas (pelo menos numa parte importante da sua expressão) ou a teorias de causalidade absolutas e unidireccionadas. A teoria dos jogos, por exemplo, veio fazer encarar numa perspectiva diferente alguns desses processos. Mas a ilógica das decisões, sobretudo ao nível das interacções microsociais, necessita porventura de ser trabalhada com outros instrumentos. De qualquer maneira, Raymond Boudon (1971: 4), ao debruçar-se sobre a incerteza das associações causais entre fenómenos sociais, defende que a sociologia apenas pode chegar a uma «teoria das implicações fracas». Por mais que nela se pretenda formular um corpo de proposições integradas e irrefutáveis, em termos de lógica dedutiva, tal objectivo não é facilmente atingido. Para ele é claro que «[a] natureza do social nunca permite observar implicações estritas» (Boudon 1971: 18).

Estas questões, e outras semelhantes, têm vindo a ser reflectidas por matemáticos e cientistas sociais. Hoje fala-se, por exemplo, de conjuntos imprecisos, tema importante para ambas as ciências. Mas o próprio conceito de imprecisão (fuzziness) é complexo, pois nem se identifica com probabilidade, no sentido de frequência, nem se distingue sempre de probabilidade subjectiva ou se confunde com a ambiguidade ou falta de intersubjectividade. Por outro lado, é distinto de algumas espécies de generalidade (cf. Smithson 1987: 13).

O desenvolvimento de alguns métodos e algoritmos específicos relacionados com esta temática - designadamente em A Ciência do Impreciso, de Abraham Moles (1995) e em Fuzzy Sets for the Behavioral and Social Sciences, de Michael Smithson (1987) - tem em conta a natureza imprecisa de muitos factos sociais, cuja análise está longe de poder cumprir a regra da clareza e distinção recomendada pela metodologia cartesiana, ou de levar a uma teoria da causalidade estrita. Mas estes métodos permitem esperar uma definição mais adequada das coisas.

No mesmo contexto se pode falar de uma outra teoria emergente, a das facetas, ou seja, os aspectos ou características de uma situação, em que é tomada em linha de conta, por exemplo, «a positividade dos eventos, 
o seu número, a sua variabilidade e a dificuldade em os tratar» (Borg e Shye 1995: 2). De acordo com esta teoria, seria importante a noção de perfis ou estructuplos, ou seja, a «combinação dos elementos das facetas, individualmente tomados em cada uma» (Borg e Shye 1995: 2).

Não é obviamente este o lugar apropriado para o desenvolvimento das questões levantadas por este conjunto, antigo e recente, de instrumentações matemáticas. A sua importância para o nosso tema pode, no entanto, ser entrevista através de duas improcedências, significadas pelo efeito de Condorcet e pelo paradoxo de Simpson. O primeiro, posto em evidência por um dos «primeiros utilizadores da matemática nas ciências sociais», mostra que, quando pedimos a um grupo de pessoas que ordene três objectos por ordem de preferência, frequentemente acontece que as suas opções são incompatíveis entre si, de sorte que «preferências individuais coerentes tornam-se incoerentes quando se juntam» (Boudon 1971: 4). Por outro lado, Simpson notou que pode haver «uma associação positiva marginal entre duas variáveis binárias $\mathrm{B}$ e C, embora em função de uma terceira variável, A, a associação entre C e B possa ser negativa» (cf. Cox 1992: 291).

Tanto o efeito de Condorcet como o paradoxo de Simpson mostram que a associação e a causalidade podem conduzir a erro, sendo frequentemente necessário decompor os fenómenos por forma a compreender as suas verdadeiras interacções, reforços e debilitações mútuas. A noção de causalidade supõe que uma variável está associada a uma ou mais características de um fenómeno. Mas esta relação depende de muitas circunstâncias em que o efeito pode ser anulado. Por outro lado, o importante não é estabelecer os termos extremos dos efeitos produzidos, mas definir as intermediações existentes, para já não falar dos efeitos retroactivos, entendidos em termos sistémicos e não temporais.

Nenhuma destas clarificações metodológicas poderá ser levada a cabo sem uma ordenação teórica dos diversos condicionamentos em causa, o que implica a definição prévia da teia dos efeitos causais, a sua reciprocidade e retroactividade eventuais. Para além disso, é necessário verificar em que sentido a causalidade se verifica, podendo acontecer, como refere Rosenblatt (cf. Cox 1992: 293-294), que determinados sistemas não lineares sejam determinísticos numa direcção e estocásticos noutra, caso se inverta a variável tempo.

O papel do cientista está assim na definição da cadeia teórica das relações entre os fenómenos, num modelo em que a realidade é considerada interagente, ou, numa linguagem mais antropológica, intersignificativa. Neste mesmo sentido se podem formular modelos que podem ser considerados «potencialmente causais» (Cox 1992: 294), para o que será 
necessário distinguir variáveis imediatas, intermédias e envolventes, cada uma delas com uma distância específica em relação aos efeitos produzidos. Assim, a definição das mediações de causalidade não pode ser substituída pelo «ver se dá» em «corridas de programas» não suportadas por relações teóricas claras entre as variáveis.

\section{Tipos E ATRIBUTOS}

Algumas das dificuldades anteriormente assinaladas são particularmente visíveis nas análises tipológicas, teorizadas, entre outros, por Max Weber, as quais têm vindo a ser utilizadas de uma forma extensiva nos métodos de análise factorial e de «clusters». Na perspectiva weberiana, tal procedimento recomenda-se porque os tipos ideais correspondem a um «complexo que é entendido como um sistema internamente consistente». Para ele, «este constructo é em si mesmo como uma utopia a que se chegou pela acentuação analítica de certos elementos da realidade» (Weber 1949: 90), procedendo-se na sua definição a uma espécie de polarização das características observadas. Daqui resulta que o tipo ideal é uma pura construção teórica que não tem outra intenção que não seja a clarificação dos conceitos.

Nos métodos factoriais, a tipologia tem a ver com a descrição interpretativa da realidade. Do conjunto, necessariamente compósito e circunstancial - pois depende das variáveis disponíveis para tal composição -, pretende-se tirar conclusões acerca das relações últimas entre as características. O método é sedutor. Através da matemática e da correlação entre os atributos constrói-se uma realidade teórica sobre os factores que lhes estão subjacentes. Não deixo, no entanto, de notar que nestas análises pode facilmente imiscuir-se o efeito de Condorcet, sobretudo se se usam modelos micro para construir explicações macro. Tomo, com efeito, como ajustada a advertência de Miller, num contexto um pouco diferente: «uma análise quantitativa dos indivíduos só pode conduzir a conclusões precisas acerca dos indivíduos; uma análise de lugares, só a conclusões precisas acerca dos lugares; e uma análise de época, a conclusões acerca das épocas» (Miller 1995: 155-156). E se é certo que a «interpretação [de um resultado estatístico] não faz frequentemente mais do que transformar noutro, com coordenadas diferentes, o espaço de atributos de um sistema tipológico, [acontece que] com isso se muda simultaneamente uma redução noutra». Ora, como diz Lazarsfeld (1993: 166), deve-se atender a que «[a]s classificações tipológicas usadas na investigação científica actual são um tanto vagas e portanto para elas pode ser fornecida mais 
do que uma substrução ${ }^{1}$ lógica. Mas os diferentes espaços de atributos provindos destas diferentes substruções podem ser transformados uns nos outros» (Lazarsfeld 1993: 166).

A construção das tipologias está, pois, marcada por dificuldades que não podem ser supridas por técnicas matemáticas que não sejam suportadas teoricamente. Lazarsfeld (1993: 166) recomenda que «quando estão em causa diversos atributos, será melhor [de preferência a escolhê-los, à partida] que o estudioso se familiarize em profundidade com o material, ordenando-o em seguida em alguns tipos principais numa base inteiramente impressionista. Só depois deverá reconsiderar a matéria, substruturar as suas próprias intuições tipológicas num espaço de atributos adequado e pôr em evidência a redução que usou implicitamente. Os melhores resultados serão provavelmente obtidos justamente na combinação de um inquérito genérico e de uma análise sistemática subsequente.» A questão fundamental está em que o espaço de atributos que permitem uma tipologização é por natureza multidimensional. Nenhuma redução a que se queira proceder, por mais automática que seja, elimina a necessidade de ser liderada teoricamente, não permitindo que os casos postos de lado, por não concretizarem algumas das características, venha a inviabilizar as relações descobertas.

\section{FELICIDAde E RELIGIÃo}

Estes elementos relativos à análise de dados de opinião levam-me a concretizar melhor o que pretendo dizer através de algumas considerações sobre as associações supostas num trabalho do Instituto de Ciências Sociais (Cabral et al. 2000), cujos principais resultados foram divulgados numa conferência de imprensa no dia 17 de Março de $2000^{2}$. O facto de se tratar de uma investigação sociológica de vulto e de, nessa apresentação, terem sido formuladas algumas conclusões surpreendentes, suportadas pela utilização de uma metodologia tipológica, justificam estas reflexões. Com efeito, nas notícias das televisões e dos jornais sobre o evento foi referido que o estudo revelava que os católicos praticantes eram

${ }^{1} \mathrm{O}$ conceito de substrução, sugerido por Hempel e Oppenheim, é o seguinte: «O procedimento para encontrar num determinado sistema de tipos o espaço de atributos a que pertence a redução que implicitamente foi usada» (Lazarsfeld 1993: 162). A redução é «um agrupamento de combinações de atributos que envolve mais de um atributo» (Lazarsfeld 1993: 161).

${ }^{2}$ Agradeço ao professor José Machado Pais o ter-me facultado este estudo (Pais 2000). 
infelizes. A notícia baseava-se não só no que foi então afirmado, mas também no já referido trabalho de Machado Pais. Entre as características por ele referidas na figura 1 , intitulada «As teias da religiosidade conservadora: católicos ritualistas, moralistas e tradicionais», é dito serem eles, entre outras coisas, «nada felizes», pensarem que o «mundo está cheio de maldade e de pecado» e que «o destino não se altera» (Pais 2000: 24). Por oposição, os laicos «urbanos e elitistas» (figura 3) são «bastante felizes», pensam «que a vida faz sentido sem Deus» e têm «expectativas elitistas» (Pais 2000: 24). O autor afirma ainda que «o dado mais saliente se prende com o facto de $58 \%$ dos Portugueses que se acham 'nada felizes' com a sua vida se encontrarem no grupo dos católicos ritualistas» (Pais 2000: 11). O contrário acontece com os laicos urbanos e elitistas: «Ao pensarem em todos os aspectos da sua vida actual, $62 \%$ consideram-se bastante felizes» (Pais 2000: 17).

$\mathrm{O}$ que parece estar contido em tal leitura, sobretudo nas figuras mencionadas, é que há uma relação negativa entre religião e felicidade. Só quem não acredita em Deus e não reza é feliz. Assim, rapidamente se passa à ideia de que o catolicismo é causa de infelicidade. O que não é dito é que só $8,2 \%$ de todos os católicos, ritualistas ou não, se considera «nada feliz». Por outro lado, tomando os resultados do inquérito pelo seu valor facial, chegaríamos à conclusão de que os seguidores de outras religiões não cristãs são menos felizes do que os católicos: $11,1 \%$ confessam-se «nada felizes». Acima de todos em termos de infelicidade estariam os protestantes: $33,3 \%$ têm esse mesmo sentimento de ausência total de felicidade ${ }^{3}$.

$\mathrm{Se}$, por outro lado, agregarmos as categorias dos que se dizem «pouco» ou «nada» felizes e as cruzarmos pela sua posição religiosa, verificamos que os católicos não têm as mais altas percentagens. Contra $43,8 \%$ de católicos pouco ou nada felizes, há $61,9 \%$ de protestantes e outros cristãos e $55,5 \%$ de sequazes de outras religiões na mesma situação. Apenas os que não têm nenhuma religião têm menor percentagem $(28,3 \%)$ do que os católicos ${ }^{4}$. Em contraponto com isto, temos as pessoas que se

${ }^{3}$ Os cálculos aqui apresentados utilizam todos os casos referidos na sondagem ICS (Cabral et al. 2000) sem os ponderar. A ponderação apenas ocultaria problemas de representatividade que a amostra efectivamente tem.

${ }^{4}$ Os valores dos testes estatísticos para a tabela de contingência das quatro categorias de religião («protestante/outra cristã», «católica», «outra não cristã» e «nenhuma») pelos quatro graus de felicidade («muito feliz», «razoavelmente feliz», «pouco feliz» e «nada feliz») são os seguintes: $\chi^{2}=33,807$; g.l. $=9 ; \mathrm{p}=0.000$; phi: 0,169; contingência: 0,167; Gamma: -0,227; Spearman: $-0,090$. 
consideram «muito felizes»: protestantes e outros cristãos: $14,3 \%$; católicos: 19,4\%; sem religião: 19,6\%; outros não cristãos: $33,3 \%$. Neste aspecto, as pessoas sem religião não estão melhor do que os católicos e são menos felizes do que os seguidores de outras religiões. Por outro lado, no que se refere a esta última categoria, o resultado - $33,3 \%$ de pessoas felizes - introduz uma contradição com os 55,5\% "pouco» e «nada» felizes do mesmo grupo.

Seja como for, estes dados não sustentam a associação estabelecida entre catolicismo e infelicidade. $\mathrm{O}$ valor facial dos dados diz que o catolicismo está associado a menor infelicidade do que as religiões que não o catolicismo e que, se os urbanos elitistas atingem maiores percentagens de «razoavelmente felizes» $(52,2 \%)$, os católicos têm $36,8 \%$ na mesma categoria, contra os $23,8 \%$ dos protestantes e os $33,3 \%$ das religiões não cristãs. No entanto, a estatística conjunta dos «muito» e «razoavelmente» felizes é favorável aos urbanos irreligiosos e elitistas, já que $71,8 \%$ estão nestas duas categorias, contra $56,2 \%$ de católicos, $44,4 \%$ de outras religiões e $38,1 \%$ de protestantes. Estes resultados alertam-nos para algumas contradições que interessará aprofundar, designadamente no sentido de verificar se não há outras variáveis mais fortemente definidoras das variações nos sentimentos de felicidade.

\section{A IRRELEVÂnCIA daS PRÁtica RELIGIOSAS NA FELICIDAde}

Convém insistir que não se pode desvincular a interpretação de qualquer sondagem das considerações metodológicas feitas acima. As relações entre os elementos constituintes de uma teoria dependem do estatuto teórico das variáveis, querendo isto dizer que as causas ou os condicionamentos dos fenómenos podem ser ou não mediados. Não se pode fazer uma teoria da implicação, da associação ou da causalidade se não se tiver uma ideia acerca de quão mediata ou imediatamente os sentimentos, as atitudes e os comportamentos estão relacionados com variáveis de natureza mais ou menos objectiva. Por outras palavras, uma boa estratégia de análise obriga a clarificar pelo menos três questões: 1 . o modelo utilizado: causalidade, implicação, ou associação; 2. o estatuto teórico das variáveis e a cadeia de relações supostas; 3 . a retroacção dos efeitos.

Não poderei obviamente desenvolver aqui tudo o que está implicado nestas questões. Mas não tenho dúvidas em dizer que as variáveis materiais, designadamente aquelas que têm a ver com as condições de vida, podem aparecer aos actores sociais como mais directamente 
associadas aos seus sentimentos de felicidade ou infelicidade do que as relacionadas com constructos culturais abstractos. Nas coisas sociais, o que parece é. Os factos do dia-a-dia são governados por teorias implícitas elaboradas por cada um dos actores sociais. $O$ que se não toca dificilmente se interioriza e teoriza. As apreciações e avaliações da situação decorrem de comparações que os actores estabelecem com o que têm à sua volta.

Aplicando estes pressupostos, dir-se-ia, de forma simplificada, que uma situação penosa não favorece a apreciação da felicidade, muita ou pouca, que porventura se tenha. Ao teórico implícito que é cada inquirido - a matéria prima de análise é o que pensa, sabe e diz de si mesmo as variáveis de natureza cultural, entre as quais as religiosas, são demasiado longínquas para que reconheça a sua importância estratégica na definição da sua felicidade, sendo, como são, mediadas pelas condições materiais de vida. Ou seja, as características psicológicas dos actores e as suas atitudes têm a sobredeterminá-las o sistema social, que delas constitui a referência imediata. A cultura, por seu lado, interfere na diferenciação dos comportamentos ao permear as estruturas com as legitimações e justificações que levam à aceitação do sistema.

Se assim é, compreende-se que as concepções e atitudes religiosas, constitutivas da referência última do sistema cultural, tenham importância própria, mas não muito manifesta ou aparente. Em meu entender, só há dois casos em que a religião poderia ser claramente determinante do sentimento de felicidade: (i) quando a vida social fosse determinada por uma moral anti-humana, imposta por instituições sociais totalitárias, que conduzissem ao total domínio do indivíduo; (ii) ou quando, no outro extremo, a união mística determinasse a vida das pessoas, o que configuraria a suma felicidade. Fora destas situações, a relação entre felicidade e religião é sempre equívoca.

Estas afirmações levam-me a considerar que a clarificação dos conceitos utilizados é tanto mais necessária quanto os dados são imprecisos e relacionados entre si de forma não inteiramente perceptível ou mensurável. Mas esta tarefa nem sempre é possível, dada a natureza difusa de alguns comportamentos.

Segundo o desígnio metodológico implicado nestes considerandos, procedeu-se ao estudo da significância das variações do sentimento de felicidade, tal como foi expresso pelos respondentes ao inquérito em causa, em função de algumas variáveis que concretizam a teoria aqui desenvolvida. Os resultados obtidos confirmam as dúvidas levantadas no ponto anterior, onde no entanto verificámos haver significância na distribuição dos sentimentos de felicidade em função da religião professada. 
Um dos aspectos em que a pertença religiosa pode ser mais claramente detectada, em termos das questões do inquérito, são as idas à igreja, que admitiam as seguintes categorias: « 1 ou mais vezes na semana», « 2 ou 3 vezes na semana», «1 vez por mês, algumas vezes no ano», «menos de algumas vezes por ano» e «nunca». No que se refere aos que se sentem «muito felizes», segundo tais categorias, temos, por ordem, as seguintes percentagens: $21,5 \%, 17,6 \%, 10,3 \%, 20,0$ e $15,6 \%$. As pessoas do primeiro grupo são, pois, as mais felizes, seguidas de perto apenas pelas que vão à igreja menos de uma vez por ano. Por outro lado, as pessoas que nunca vão à igreja não são as mais felizes. Paralelamente, as pessoas que se dizem «nada felizes» atingem, pela ordem referida, os seguintes valores: $9,8 \%, 8,4 \%, 10,3 \%, 7,3 \%, 11,2 \%$ e $3,1 \%$. Por estes dados se vê serem as pessoas que vão menos de uma vez por ano à igreja as menos felizes ${ }^{5}$.

O que ressalta destes dados, e dos não comentados relativos às categorias intermédias (razoavelmente e pouco feliz), é que as diferenças são demasiado pequenas para serem significativas. Nenhum dos testes aplicáveis às variáveis ordinais tem significância. A probabilidade dos testes $d$ de Somer, Tau b e Tau $c$ de Kendall, Gamma e Spearman é de $40 \%$. Os valores Gamma e Spearman são respectivamente -0.027 e -0.024 , não sustentando, por isso, nenhuma conclusão sobre qualquer associação ou sobre o seu sentido.

\section{FACTORES NÃO RELIGIOSOS DA FELICIDADE}

A hipótese formulada anteriormente a respeito da influência das condições de vida nos sentimentos de felicidade pode ser avaliada através da associação entre estes sentimentos, por um lado, e a classe social e o rendimento familiar, por outro, sendo estas duas variáveis tomadas como expressões das condições de vida, a primeira mais mediata do que a segunda. Segundo a hipótese, o rendimento familiar estaria mais fortemente associado à felicidade do que a classe social, o que efectivamente se verifica, como passo a mostrar, anotando antes, para o bom entendimento dos resultados referentes à classe social, que ela não foi definida a posteriori pelos investigadores, mas resulta da autoclassificação

${ }^{5}$ Tomando esta distribuição, juntamente com a das categorias «razoavelmente feliz» e "pouco feliz», obtemos os valores: $\chi^{2}=19.835$; g.1. $=15 ; \mathrm{p}=0.178$. Note-se ainda que as duas primeiras categorias estão invertidas, em termos de ordem lógica, o que para o caso não é irrelevante. 
dos inquiridos. Este facto introduz, por si só, alguma imprecisão nos dados. Mas isso não é específico daquela variável. Também os sentimentos de felicidade ou infelicidade que os inquiridos dizem ter resultam de classificações fluidas.

Quadro 1 - Percentagens de sentimentos de felicidade segundo a classe social subjectiva

\begin{tabular}{lrrrrrrr}
\hline Grau de felicidade & $\begin{array}{c}\text { Classe } \\
\text { baixa }\end{array}$ & $\begin{array}{c}\text { Classe } \\
\text { traba- } \\
\text { lhadora }\end{array}$ & $\begin{array}{c}\text { Classe } \\
\text { média } \\
\text { baixa }\end{array}$ & $\begin{array}{c}\text { Classe } \\
\text { média }\end{array}$ & $\begin{array}{c}\text { Classe } \\
\text { média } \\
\text { alta }\end{array}$ & $\begin{array}{c}\text { Classe } \\
\text { alta }\end{array}$ & Total \\
\hline Muito feliz & 5,6 & 22,1 & 21,9 & 21,4 & 34,6 & 3,8 & 19,7 \\
Razoavelmente feliz & 24,3 & 32,0 & 32,1 & 50,3 & 50,0 & 50,0 & 37,3 \\
Pouco feliz & 50,7 & 38,5 & 39,4 & 23,7 & 15,4 & 26,9 & 35,0 \\
Nada feliz & 19,4 & 7,4 & 6,6 & 4,6 & 0,0 & 19,2 & 8,1 \\
\hline
\end{tabular}

Fonte: Cálculos sobre Cabral 2000

O certo é que a percentagem de pessoas da classe média alta muito felizes é cerca de 7 vezes maior que a da classe baixa. Por outro lado, a percentagem das classes trabalhadora, média baixa e média, muito felizes é muito semelhante, possivelmente porque as diferenças de classe também não são importantes. O reverso da medalha, relativo aos pouco felizes, também é verdadeiro, o que confirma a hipótese: as pessoas da classe baixa são confessadamente muito mais infelizes do que as das outras classes, excepção feita à classe alta, fundamentalmente constituída pelos urbanos elitistas referidos acima, o que parece contraditório. Todos os testes mostram que as variações são estatisticamente significativas ${ }^{6}$.

O segundo indicador das condições de vida é o rendimento familiar. Em termos hipotéticos, é de admitir uma associação positiva entre felicidade e rendimento e que esta associação é mais importante que a existente entre felicidade e classe social, dado que, por um lado, a definição da classe é mais fluida do que o rendimento e, por outro, incorpora muito mais componentes, o que se pode traduzir em efeitos contraditórios em relação aos sentimentos de felicidade. No conjunto, estas propostas interpretativas confirmam-se.

${ }^{6}$ As estatísticas são as seguintes: $\chi^{2}=115.965$; g.l. $=15 ; \mathrm{p}=0.000$; Gamma: -0.252 ; Spearman: -0.209 . 
Quadro 2 - Percentagens de sentimentos de felicidade segundo o rendimento familiar (em contos)

\begin{tabular}{lrrrrrrr}
\hline Grau de felicidade & $<31$ c. & $\begin{array}{r}31- \\
60 \text { c. }\end{array}$ & $\begin{array}{r}61- \\
100 \text { c. }\end{array}$ & $\begin{array}{r}101- \\
160 \text { c. }\end{array}$ & $\begin{array}{r}161- \\
300 \mathrm{c} .\end{array}$ & $>300 \mathrm{c}$. & \multirow{2}{*}{ Total } \\
\hline Muito feliz & 5,1 & 13,8 & 18,5 & 19,5 & 23,9 & 29,9 & 19,7 \\
Razoavelmente feliz & 25,6 & 22,2 & 29,2 & 42,5 & 44,5 & 51,5 & 36,8 \\
Pouco feliz & 48,7 & 44,3 & 41,3 & 35,5 & 27,3 & 17,5 & 35,4 \\
Nada feliz & 20,5 & 19,8 & 11,0 & 2,6 & 4,2 & 1,0 & 8,0 \\
\hline
\end{tabular}

Fonte: Cálculos sobre Cabral 2000

O quadro 2 mostra, com efeito, que a percentagem de pessoas que se consideram muito felizes cresce monotonicamente com o rendimento familiar. A percentagem de muito felizes com mais de 300 contos de rendimento é cerca de 6 vezes maior do que a de pessoas com menos de 31 contos. Exactamente o contrário aparece na categoria «nada feliz». Usando tal indicador dir-se-ia, forçando um pouco os termos, que as pessoas com menos de 31 contos de rendimento são vinte vezes menos felizes do que as que têm 300 contos ou mais de rendimento ${ }^{7}$.

É, por outro lado, de assinalar o facto de os inquiridos, na sua globalidade, se confessarem mais felizes do que infelizes: a percentagem daqueles que se dizem nada felizes $(8,0 \%)$ é mais de duas vezes inferior à daqueles que se dizem muito felizes $(19,7 \%)$. Regista-se, por outro lado, que as variações em causa não decorrem de erros intrínsecos à amostra.

Este conjunto de resultados relativos à significância das distribuições e referentes às três variáveis estudadas (frequência das idas à igreja, classe social e rendimento) levou a verificar que tanto o valor de $\chi^{2}$ como o das estatísticas Gamma e Spearman crescem em função da incorporação das condições materiais de existência nas variáveis utilizadas.

Assim, o rendimento seria a variável com mais força explicativa, como se pode verificar pela síntese das estatísticas apresentadas no quadro 3 . A seguir viria a classe social. No pólo da insignificância estaria a frequência da igreja, a qual não diferenciaria suficiente e significativamente as pessoas em termos de sentimentos de felicidade.

${ }^{7}$ As estatísticas são as seguintes: $\chi^{2}=125.452$; g.1. $=15 ; \mathrm{p}=0.000$; Gamma: -0.313 ; Spearman: -0.277 . 
Quadro 3 - Testes de associação entre variáveis da base de dados ICS

\begin{tabular}{lrrrrr}
\hline \multicolumn{1}{c}{ Associação } & \multicolumn{1}{c}{$\chi^{2}$} & g.1. & p & Gamma & Spearman \\
\hline Felicidade/frequência da igreja & 19,84 & 15 & 0,18 & $-0,027$ & $-0,024$ \\
Felicidade/classe social subjectiva & 115,97 & 15 & 0,00 & $-0,252$ & $-0,209$ \\
Felicidade/rendimento familiar & 125,45 & 15 & 0,00 & $-0,313$ & $-0,277$ \\
\hline
\end{tabular}

\section{CONCLUSÃo}

Constituindo estes breves apontamentos apenas o início de um possível estudo sobre as condições da felicidade, não poderemos tirar conclusões definitivas sobre os méritos dos processos utilizados. Mas os resultados obtidos permitem chamar a atenção para o facto de os pressupostos e os métodos de análise terem óbvias consequências nas teorias desenvolvidas, sobretudo em matérias onde o efeito de Condorcet ou o paradoxo de Simpson espreitam continuamente a desatenção do analista. Por outro lado, o exemplo estudado parece mostrar que, em termos da utilização da matemática na construção das teorias sociais, as teias do significado só podem ser tecidas por Penélopes incansáveis que, no fazer e refazer constante das teorias, vão encontrando novos sentidos - o mais das vezes ocultos, como em Delfos - que subjazem aos comportamentos sociais, em seus enquadramentos institucionais e sobredeterminações culturais.

$\mathrm{O}$ percurso feito - da crítica da construção do objecto à sua interpretação - revelou alguns dos escolhos que se encontram em todas as investigações relativas às relações entre ideias, sentimentos, atitudes e suas condicionantes sociais. Por outro lado, mostrou que as relações entre os factos podem ser obnubiladas por variáveis compósitas e de imprecisa definição, sendo a análise perturbada pela incompatibilidade das opções e pela contaminação contraditória de dependências culturais múltiplas.

O eventual mérito da análise realizada estará no estabelecimento de relações entre variáveis singelas, onde as associações podem ser mais claramente entrevistas. A partir delas, outras mais complexas poderão ser estudadas, devendo no entanto atender-se sempre a que os resultados não podem ser contraditórios nem afastar-se muito do senso comum, que nunca é tão erróneo como uma análise superficial pode fazer crer.

Por outro lado, as associações descobertas parecem encaminhar a interpretação para formulações conformes com a teoria disponível. Além disso, estas aproximações simples parecem indicar que a complexidade 
dos métodos não garante a correcção do que não pode ser sustentado pela teoria.

Mas a questão de fundo, aqui tocada muito ao de leve, é que o conhecimento científico das causalidades, implicações ou associações entre ideias, sentimentos, atitudes, comportamentos, determinações institucionais, traços culturais, valores e símbolos sociais - a teia sócio-cultural - não se compadece com leituras apressadas. É fruto de uma longa paciência. E o seu principal instrumento é a matemática, onde a lógica é levada às últimas consequências.

\section{Referências}

Alker, JR., Hayward R., Karl W. Deutsch, Antoine H. Stoetzel, eds. (1973) - Mathematical Approaches to Politics, Amsterdão, Elsevier.

Berk, Richard A. (1988) - Causal Inference for Sociological Data, in Neil J. Smelser, ed., Handbook of Sociology, Londres, Sage, pp. 155-172.

Borg, Igwer, Samuel Shye (1995) - Facet Theory, Form and Content, Londres, Sage.

Boudon, Raymond (1971) - Les mathématiques en sociologie, Paris, PUF.

Brass, W. (1974) - Perspectives in Population Prediction, Illustrated by the Statistics of England and Wales, Journal of the Royal Statistical Society, Series A, 137 (4), pp. 532-570.

Cabral, Manuel Villaverde, Jorge Vala, José Machado Pais e Alice Ramos (2000) - Atitudes e Práticas Religiosas dos Portugueses, Base de dados 2, Lisboa, Imprensa de Ciências Sociais.

Coale, Ansley J., T. James Trussell (1978) - Technical Note: Finding the Two Parameters that Specify a Model Schedule of Marital Fertility, Population Index, 44, pp. 203-213.

Coleman, James S. (1964) - Introduction to Mathematical Sociology, Glencoe, The Free Press.

Cox, D. R. (1992) - Causality: Some Statistical Aspects, Journal of the Royal Statistical Society, Series A, 155 (2), pp. 291-301.

Halley, Edmund (1693) - An estimate of the degree of the mortality of mankind, in David Smith, Nathan Keyfitz, eds., Mathematical Demography, Selected Papers, Berlim, Springer-Verlag, 1977, pp. 21-26.

Lazarsfeld, Paul F. (1993) (1972) - Some Remarks on Typological Procedures in Social Research, in suo On Social Research and its Language, Chicago, The University of Chicago Press, pp.158-172.

Lotka, Alfred J. (1998) - Analytical Theory of Biological Populations, Nova Iorque, Plenum Press, 220 p. [1.a ed.: 1934]. 
Merton, Robert K. (1957) - Social Theory and Social Structure, Glencoe, The Free Press.

Miller, W. L. (1995) - Quantitative Methods, in David Marsh \& Gerry Stoker, eds., Theory and Methods in Political Science, Londres, MacMillan, pp. 154-172.

Moles, Abraham (1995) - As ciências do impreciso, Porto, Afrontamento.

Pais, José Machado (2000) - O que explica a religiosidade dos portugueses, Um ensaio de análise tipológica, manuscrito, 48 p.

Russell, Bertrand (1972) (1903) - The Principles of Mathematics, Londres, G. Allen \& Unwin.

Sanders, David (1995) - Behavioral Analisys, in David Marsh \& Gerry Stoker, eds., Theory and Methods in Political Science, Londres, MacMillan, pp. 58-75.

Smithson, Michael (1987) - Fuzzy Set Analysis for Behavioral and Social Sciences, Nova Iorque, Springer-Verlag.

Thomas, W. I., \& F. Znanieecki (1998) - Le paysan polonais en Europe et en Amérique, Recit de vie d'un migrant (Chicago 1919), trad. de Ives Gaudillat, Paris, Nathan.

Weber, Max (1949) - The Methodology of the Social Sciences, trad. E. Shils \& H. Finch, Nova Iorque, The Free Press. 
(Página deixada propositadamente em branco) 


\section{$\begin{array}{llllll}\text { C I E } & \mathbf{N} & \mathbf{C} & \mathbf{A}\end{array}$}

mitiram realizar com sucesso tarefas tão distintas como a programação de um voo a Marte, a previsão de resultados eleitorais, a explicação do funcionamento de alguns mecanismos do sistema nervoso, ou a abordagem critica de obras de arte e de textos literários. Da ciência à sociedade, dos grandes avanços técnicos à solidez de uma argumentação lógica, a Matemática constrói teias de uma imensa flexibilidade resultante do carácter universal da sua linguagem.

Neste livro, personalidades de diferentes universos dão o seu testemunho sobre a forma como usam as teias matemáticas para tecer a sua própria visão do mundo.

Maria Paula Serra de Oliveira é professora de Matemática na Faculdade de Ciências e Tecnologia da Universidade de Coimbra. 